\title{
Analyzing the Reversal of Public Opinion in the Internet Era From "Bao Yuming's Alleged Sexual Assault Case
}

\author{
Yuan Yao $^{1} \&$ Wenzhi Sun ${ }^{1}$ \\ ${ }^{1}$ Southwest Petroleum University, Sichuan, China \\ Correspondence: Yuan Yao, Southwest Petroleum University, Sichuan, China. E-mail: 408964160@qq.com
}

Received: January 19, 2022

Accepted: February 15, 2022

Online Published: February 27, 2022

doi:10.20849/ajsss.v7i2.1007

URL: https://doi.org/10.20849/ajsss.v7i2.1007

\begin{abstract}
With the rapid development of the Internet in China in recent years, the public tends to get information about news events from the Internet and publish their opinions on online social platforms. Guiding people's public opinion in the online world has become an essential social proposition. We choose the "Bao Yuming's alleged sexual assault case," which caused an intense social discussion on the Chinese Internet in 2020, as a case study for analysis and analysis of the various public opinion phenomena that emerged in society at that time discuss their causes and background. Finally, we propose ways to guide the case from three aspects.
\end{abstract}

Keywords: reversal of public opinion, news dissemination, public opinion supervision

\section{Introduction}

\subsection{Introduction of the Problem and Its Importance}

On April 9, 2020, a media organization called "Southwind Window" published the news story "Three years of alleged sexual abuse of a minor daughter, revealing the "skin" of the president's father," which sparked a heated discussion in Chinese social media networks. During the year-long review of the case, various opinions and rumors emerged on the Internet. Eventually, the official investigation results were released, leading to a massive case reversal. At the same time, such reversal news cases have occurred frequently in recent years. We selected one of these very representative social news reversal cases in recent years for analysis, which can provide a reference for the guidance and solution of similar social problems in the future.

\section{Background of the Case Under Discussion}

On April 9, 2020, the official microblog of "Southwind Window" published a lengthy article, "Suspected of sexually abusing his underage daughter for three years, unveiling the "skin" of the president's father," which aroused the attention of netizens. On April 12, 2020, Caixin.com published an article titled "Suspicion of Sexual Abuse of "Adopted Daughter" by Executive," which added a particular dimension to the case from the perspective of the accused Bao Yuming. On April 13, the Supreme People's Procuratorate and the Ministry of Public Security sent a joint supervisory team to Shandong to handle Bao's alleged sexual assault.

On August 13, the girl's age is in doubt; some netizens found Li Xingxing suspected of having two identity cards, respectively, August 20, 2001, and October 1, 1997. On September 17, the Supreme People's Procuratorate, the Ministry of Public Security joint supervision group, informed the investigation of this case: the existing evidence can not confirm that Bao's behavior constitutes the crime of sexual assault. Bao Yuming's lawyer's license was revoked and deported, and the sexual assault was not established.

After a thorough investigation, the available evidence could not confirm that Bao's behavior constituted a sexual assault offender. Only since then has the nearly six-month-long case finally come to an end.

\section{Research on the Evolution of Public Opinion on Chinese Networks and the Law}

\subsection{The Driving Role of the Law of Emotion in the World of Public Opinion}

In the world of public opinion, emotion prevails over reason. Generally speaking, emotion dominates the world of public opinion. Public opinion shows an extreme, one-sided tendency due to emotional irrationality.

We can take the south wind window in this event as an example; on April 9, 2020, 'south wind window' released Changwon' suspected sexual assault of minor daughter for three years, after uncovering the president's father's 
'canvas,' caused intense discussion on a microblog. In this article, the south wind window tells how underage girls are controlled and raped by 'animals' adoptive fathers from the perspective of girl Li Xingxing. This article uses multiple personal and subjective modifications and adjectives in the present position. The majority of Internet users in the article, into their own emotions, set off a huge storm of public opinion on the Internet. The majority of netizens take the perspective of Li Xingxing into self-feelings and publish their views on Weibo, WeChat, Douban, and other social networking sites, such as 'Stick Li Xingxing,' 'Voice for Li Xingxing' and so on. Anger swept the network world, and few netizens in the enormous emotional power can calmly think about the truth of the event is what, the south wind window article is flawed.

\subsection{Women's Perspective Under the Weak Theorem}

The world of public opinion in communication reverses the primary and secondary reality and is weak in food and meat. Strength and weakness are the essential attributes and core relationships in public opinion. All features and relationships can be converted to strengths and weaknesses. In this Bao Yuming incident, Li Xingxing and Bao Yuming had a massive gap in the whole society, and just the strength of the public opinion world was inverted from the strength of the real world. The strong, in reality, was just the weak in public opinion. Therefore, the energy of public opinion moves in the direction conducive to the vulnerable, Li Xingxing got a huge flow advantage, and people's solidarity and media support in the field of public opinion.

From this case to the previous sexual harassment and sexual assault cases, it is not difficult to see that women are in a weak position in most cases due to their physiological and social factors. Women are more willing to speak on public social media platforms to protect their rights and security in the public opinion field. Throughout the game of public opinion in this case, for six months, the display of women's s discourse power is far greater than that of men. We can understand that the opportunities for women to receive education have significantly increased after social liberation and reform and opening up, and the awakening of group consciousness and the demand for self-rights protection are reflected in the Internet era.

\subsection{The Golden Rule of Public Opinion: The Gossip That Satisfies People's "Prying Eyes"}

The world of public opinion is a world of communication that avoids weight. In the world of public opinion, light and sober judgment and the natural world are inverted. What matters in the real world is not necessarily the world of public opinion. What is not essential in the real world, the world of public opinion may be necessary. That is to say, 'light' things best spread.

In the Bao Yuming event, one of the critical factors to promote the spread of this event is that keywords attract can significantly attract the audience's attention, triggering the audience's discussion. In the initial reports brought by the South Wind Window, the words of 'president adoptive father,' 'young girl,' 'rape,' 'imprisonment' and 'foreign executives' were brought into the public view. In subsequent media follow-up reports, 'foster care,' 'religious forces' and other keywords are presented publicly. Many of these keywords are not decisive and critical to the case itself. Still, these keywords undoubtedly arouse the public interest, triggering in-depth exploration and extensive discussion of Internet users.

\section{The Power Game of Multiple Parties in the Case}

\subsection{The Purpose and Demands of Li Xingxing's Party}

Li Xingxing himself took the initiative to accept the interview of Nanfeng Window and allowed it to be published in public. In the interview with the media, he lied about the fact that he had changed his age and described himself as an underage girl who knew nothing about the world. Fake foster relationships into imprisonment and foster parenthood. She contacted the media and distorted the facts when her relationship with Bao Yuming eased and withdrew after many reports. One is to transfer the pressure of public opinion to the police, take the hat of 'poor handling' and 'to ignore the masses' for the police. The other is to continue to negotiate with Bao Yuming in this way to obtain what he wants.

\subsection{Multiple Media: Competing for Attention and Guiding Public Opinion}

Taking the reports published by three media agencies in April 2020 as an example, the first article from the south wind window's "suspected sexual assault of minor daughters for three years" uncovered the president's father's "canvas." This article cleverly uses subjective perspectives and preset positions, such as "Bao Ming, 1972, about nine meters, about 200 kilograms, tall and strong like a mountain. Li Xingxing, just over the age of 14, has not yet developed and is thin. And add a lot of emotional statements to let the audience into their emotions, triggering empathy setting off a vast public opinion on the network.

Secondly, Caixin.com published "Suspicions about the Sexual Abuse of an Adopted Daughter by a Senior 
Executive," which followed, directly characterizing the case as "a story of a girl who lacked care since childhood seeking security from her adoptive father" from the standpoint of Bao Yuming's side, and tried the case before it was judged, and made fictitious assumptions that violated the principle of objectivity and journalistic facts, repeatedly using The article also makes unreal assumptions and uses subjective and suggestive language such as "heartbroken," "worried," and "sincere." After it was published on the Internet, it was attacked by the netizens due to its excessive personal stance and was forced to delete and publicly apologize the next day. The third article from the surging news "listed company executives allegedly sexually abused his adopted daughter for four years, the police filed a case," "visit Bao Yuming Yantai residence: 200 square meters of sea view room, the door opener said Bao is not at home" is Secondly, the "doubtful cloud of the case of senior executives' sexual assault on women" released by Caixin followed closely. From the standpoint of Bao Yuming, the case was directly characterized as "a story of a girl who lacks care since childhood seeking security from her foster father." The case was not tried before trial, and it was fictionalized. In violation of objective principles and news facts, it repeatedly used subjective and suggestive languages such as "worry," "worry," and "sincerity." After being released online, it was forced to delete and publicly apologize the following day because of its overly personal stance being attacked by online friends. The third article from the surging news' listed company executives are allegedly sexually assaulted daughter four years, the police filed a case, "visit Bao Yuming Yantai residence: 200 square meters sea view house, the door opener said Bao is not at home is more outrageous, in this article reports false content, fabricated facts hurt people unrelated to the case. The false news of Li Xingxing smother giving up her daughter for the sake of wealth has triggered online violence against Li Xingxing s mother and other families.

Through these three news reports released in April, it is not difficult to see that news media have lost media institutions' most basic position and moral requirements to attract attention and discussion. Abuse their significant influence on the Internet to conduct media trials affects the judicial process and fairness and justice.

\section{Methods of Guiding Negative Public Opinion}

\subsection{Government Level}

(1) Improve relevant laws and regulations and sound mechanisms for handling unexpected public opinions

The Internet environment has developed rapidly in the past decade, but China s current relevant laws and regulations have not kept pace with development. At present, it is still not perfect, and the implementation is not strict enough. Many contents in network communication are not adequately regulated, and many media use the empty way of drilling law to fabricate false facts and obtain traffic. Still, they do not need to bear any responsibility. This situation must be supervised and restricted by law.

Secondly, in recent years, although the government has established relevant network public opinion departments and established the processing mechanism for dealing with sudden public opinion, these departments and agencies have not played their due role. Our country's ability to deal with premature public opinion is still insufficient. This large-scale and negative public opinion still spreads rapidly on the Internet. Therefore, the relevant government departments should improve the handling mechanism of sudden public opinion, absorb the experience and lessons of developed countries in this regard, and improve and perfect it in combination with China's national conditions.

\section{(2) Timely response and release of information through official channels}

The first time of the event is the best clarification time. Because negative public opinion and emotions have not been further spread and fermentation. However, in the current media ecology, many media pursue hot spots and interests first to give up exploring the actual truth and not want to publish accurate, comprehensive information. At the same time, they are also further losing the trust of the masses. In this case, the audience will expect and hope the official gives an authoritative explanation of these events.

I missed the first golden time; official media outlets in these events will further lead to the audience's distrust of government agencies and official media and even affect the future construction and development of government credibility.

So I believe that in the occurrence of the similar large-scale spread of adverse public opinion events, the official should maintain a timely and calm voice while ensuring the true and accurate content and actively guide the network public opinion towards a benign and orderly direction.

\subsection{Media Level}

(1) Raise the awareness of media responsibility and adhere to the bottom line of industry ethics 
In the current media ecology, the primary sources for the audience to obtain news information must be the mainstream media and we-media on the Internet. Therefore, they should clarify their positioning and social responsibilities and adhere to the media's s industrial ethics. First, the news media employees must be honest, fair, and rigorous to ensure truth, accuracy, objectivity, and fairness.

In the new media era, many news media, including many mainstream media, have begun to report tendentiously, emotionally, one-sidedly, and even fabricated facts to attract traffic. However, these will undoubtedly cause many false and negative public opinions to spread wantonly.

However, this will only cause the audience's distrust of the media and reduce their credibility. To improve the core competitiveness, the press must maintain and enhance its credibility. The audience can only believe in the most credible media institutions in the current Internet age. Therefore, the media should improve their professional quality, adhere to the professional ethics of journalists, maintain and improve the credibility of the press.

\subsection{Public Level}

(1) Improve personal media literacy and enhance independent thinking ability

In the current complex network environment, most of the public, as recipients and disseminators, cannot identify the truth of events. Faced with the recent massive network information, most Internet users are easily dominated by herd mentality, expressing and disseminating irrational attitudes, opinions and emotions on the Internet, which further causes the fermentation of public opinion. Therefore, it is urgent to improve the personal media literacy of Internet users and enhance their independent thinking ability.

First, in the face of complex news information, the audience should actively screen out some obvious false, vulgar news; secondly, the ability to identify and dare to question and criticize should be improved. In the face of news reports, unreasonable, illogical content can be reverse thinking.

Finally, the audience can use the diversified information channels of the network environment when the event does not show the truth and panorama, do not make the extreme evaluation, maintain a neutral attitude, listen to the views of both sides of the event, avoid being led by public opinion, so that "let the bullet fly again".

\section{Conclusion}

By analyzing Bao Yuming's s suspected sexual assault, we can see some chaos in the current Internet ecology. In the post-truth era, the reversal of public opinion has been shared. To establish and improve a healthy public opinion ecological environment, the government, the media, and the audience should work together to face unexpected adverse public opinion events actively and guide the optimistic, positive, and orderly development of network public opinion.

\section{References}

Cao, X. (2021). Research on public opinion reversal and guidance strategies in the post-truth era: the case of "Bao Yuming incident". Journalism Research Guide, 12(18), 169-171.

Dai, Y.-J., \& Lv, Z.-J. (2021). Bias and goodness: an analysis of individual behavioral motives in online attacks: the example of some female Internet users in the Bao Yuming incident. Journal of Zhejiang Shurian University (Humanities and Social Sciences), 21(6), 56-63.

Li, Y.-L., \& Chen, Y.-A. (2021). A study of online public opinion violence in reversal news: the case of Bao Yuming as an example. Journal of Yulin Normal College, 42(2), 101-105.

Liu, W. (2021). Research on countermeasures for handling police-related public opinion--analysis based on the incident of "Bao Yuming accused of sexual assault". Journal of Hunan Police Academy, 33(2), 122-128.

Sun, M.-Y., \& Song, L.-L. (2021). The motives and considerations of public opinion reversal in the post-truth era: the case of Bao Yuming as an example. Sound Screen World, (10), 25-26.

\section{Copyrights}

Copyright for this article is retained by the author(s), with first publication rights granted to the journal.

This is an open-access article distributed under the terms and conditions of the Creative Commons Attribution license (http://creativecommons.org/licenses/by/4.0/). 